\title{
Overlap in Patients With Dyspepsia/Functional Dyspepsia
}

\author{
Yasuhiro Fujiwara* and Tetsuo Arakawa \\ Department of Gastroenterology, Osaka City University Graduate School of Medicine, Osaka, Japan
}

Patients with dyspepsia/functional dyspepsia (FD) show frequent overlapping of other gastrointestinal (GI) diseases, such as irritable bowel syndrome, and non-Gl diseases, in addition to internal subgroup overlapping. These overlap patients have more frequent or more severe symptoms, poorer health-related quality of life and higher somatization scores, and they are more likely to experience anxiety, depression or insomnia compared to non-overlap patients. The higher prevalence of overlap in patients with dyspepsia/FD is not by chance, indicating common pathogeneses, including visceral hypersensitivity, altered GI motility, infection, and stressful early life events. There are few clinical trials targeting overlap in patients with dyspepsia/FD, and no therapeutic strategy has been established. Further studies in this research area are needed. In this review, we describe the epidemiology, pathogenesis and treatment of overlap in patients with dyspepsia/FD.

(J Neurogastroenterol Motil 2014;20:447-457)

Key Words

Dyspepsia; Functional dyspepsia; Gastroesophageal reflux; Irritable bowel syndrome; Overlap

\section{Introduction}

Dyspepsia is the most common upper gastrointestinal (GI) symptom, and it includes epigastric pain, fullness, discomfort, burning, early satiety, nausea, vomiting and belching. Functional dyspepsia (FD) is diagnosed when upper GI endoscopy reveals no organic lesions that might explain the dyspeptic symptoms. A systematic review found that the prevalence of FD was 11.5-14.7\% in the general population, and the prevalence of dyspepsia, lim- ited to upper abdominal pain, was estimated at $5-12 \%$ of the general population, irrespective of the presence of heartburn or regurgitation. ${ }^{1}$ According to the Rome III criteria, which is the most frequently used definition for functional GI disorders, ${ }^{2} \mathrm{FD}$ is currently divided into 2 distinct subtypes, namely, postprandial distress syndrome (PDS) and epigastric pain syndrome (EPS). PDS is defined as the presence of meal-induced dyspeptic symptoms, such as postprandial fullness and early satiation, while EPS is characterized by the presence of epigastric pain or burning sensation. ${ }^{3}$ In addition to the overlap of PDS and EPS, patients

Received: July 9, 2014 Revised: August 25, 2014 Accepted: September 10, 2014

(c) This is an Open Access article distributed under the terms of the Creative Commons Attribution Non-Commercial License (http://creativecommons. org/licenses/by-nc/3.0) which permits unrestricted non-commercial use, distribution, and reproduction in any medium, provided the original work is properly cited.

*Correspondence: Yasuhiro Fujiwara, MD, PhD

Department of Gastroenterology, Osaka City University Graduate School of Medicine 1-4-3 Asahimachi, Abenoku, Osaka 545-8585, Japan

Tel: +81-6-6645-3811, Fax: +81-6-6645-3813, E-mail: yasu@med.osaka-cu.ac.jp

Financial support: None.

Conflicts of interest: None.

Author contributions: Yasuhiro Fujiwara collected references, analyzed data, and prepared manuscript; Tetsuo Arakawa supervised the preparation of this manuscript

ORCID: Yasuhiro Fujiwara, http://orcid.org/0000-0002-1225-1785. 
with dyspepsia/FD show frequent overlapping of other functional GI disorders, as well as non-GI diseases. However, few reviews regarding overlap in patients with dyspepsia/FD currently exist.

As the definition of dyspepsia/FD has frequently changed, we have included dyspeptic symptoms, non-ulcer dyspepsia (NUD), ${ }^{4}$ uninvestigated dyspepsia and FD based on Rome $\mathrm{II}^{5}$ or Rome $\mathrm{III}^{3}$ in this review (Table 1) and have specified which criteria was used in each study if the stated. We have also divided the overlap in patients with dyspepsia/FD into the following 3 types: patients with dyspepsia/FD overlapping with GI diseases (including both upper and lower GI diseases), those with non-GI diseases and those with internal subgroup overlap. We have described the epidemiology of these 3 types of overlap and their clinical characteristics, and addressed possible common pathogenic mechanisms. Finally, we have discussed potential options for a therapeutic strategy.

Table 1. Terms of Dyspepsia/Functional Dyspepsia and Subtypes Used in This Review

Dyspepsia

Upper abdominal symptoms including epigastric pain, discomfort or burning, fullness, early satiety, nausea, vomiting and belching (retrosternal pain and heartburn were included before Rome II)

Uninvestigated dyspepsia

Patients who presents with dyspepsia that has not been investigated (generally used in epidemiological study)

Non-ulcer dyspepsia

Definition

Upper abdominal or retrostemal pain, discomfort, heartburn, nausea, vomiting or other symptom considered to be referable to the proximal alimentary tract, and lasting for more than 4 weeks, unrelated to exercise, and for which no focal lesion or systemic disease can be found responsible.

Subgroups (predominant symptoms)

Gastroesophageal reflux like dyspepsia (heartburn and epigastric burning)

Dysmotility-like dyspepsia (bloating, distention and early satiety)

Ulcer-like dyspepsia (epigastric pain)

Aerophagia

Idiopathic or essential dyspepsia

Functional dyspepsia (Rome II)

Definition

Pain or discomfort centered in the upper abdomen in the absence of organic diseases that is likely to explain the symptoms

Diagnostic criteria

At least 12 weeks, which need not be consecutive, within the preceding 12 months of: (1) Persistent or recurrent dyspepsia (pain or discomfort centered in the upper abdomen); (2) No evidence of organic disease (including at upper endoscopy) that is likely to explain the symptoms; and (3) No evidence that dyspepsia is exclusively relieved by defecation or associated with the onset of a change in stool frequency or stool form (i.e., not irritable bowel).

Subgroups (predominant symptoms)

Ulcer-like dyspepsia (upper abdominal pain)

Dysmotility-like dyspepsia (upper abdominal fullness, early satiety, bloating and nausea)

Unspecified (non-specific) dyspepsia

Functional dyspepsia (Rome III)

Definition

Presence of symptoms thought to originate in the gastroduodenal region, in the absence of any organic, systemic or metabolic disease that is likely to explain the symptoms.

Diagnostic criteria

Must include: (1) One or more of: (i) bothersome postprandial fullness, (ii) early satiation, (iii) epigastric pain and (iv) epigastric burning; and (2) No evidence of structural disease (including at upper endoscopy) that is likely to explain the symptoms. Criteria fulfilled for the last 3 months with symptom onset at least 6 months before diagnosis

Subgroups (predominant symptoms)

Postprandial distress syndrome (postprandial fullness and early satiety)

Epigastric pain syndrome (epigastric pain or burning) 


\section{Epidemiology}

\section{Internal Subgroup Overlap}

Overlap of ulcer-like symptoms, dysmotility-like symptoms and reflux-like symptoms were reported in the era of NUD. Talley et $\mathrm{al}^{6}$ reported that $43 \%$ of subjects with dyspepsia could be classified into more than one subgroup. Similarly, several studies $^{7-9}$ reported that there was considerable overlap among NUD subgroups. Although patients with reflux-like symptoms are classified into gastroesophageal reflux disease (GERD), thereafter, it should be noted that patients with ulcer-like symptoms, and those with dysmotility-like symptoms, show frequent overlapping.

Internal subgroup overlap is now recognized as overlap of PDS and EPS among patients with FD (Rome III), and Table 2 summarizes the prevalence and overlap of FD subtypes. ${ }^{10-19}$ Five studies showed that the prevalence of PDS was higher than that of EPS, ${ }^{12,13,15,16,19}$ and 4 studies found that EPS had a higher prevalence. $^{11,14,17,18}$ There was no difference in prevalence of PDS between outpatients and general population, but prevalence of EPS in outpatients was significantly higher than those in general population. Overlap between PDS and EPS varied, ranging between $5.6 \%$ and $62.3 \%$. Differences in the overlap of PDS and EPS may be owing to the choice of study subjects (outpatients or general population), or the ethnic background of the patients.
For example, Vakil et al ${ }^{18}$ strictly selected the FD patients with no endoscopic findings, as well as normal esophageal acid exposure, and normal symptom association probability (SAP) assessed via pH monitoring. ${ }^{18}$ Such strict selection might be associated with a higher level of overlap between PDS and EPS. Interestingly, overlap of PDS and EPS in outpatients was significantly higher than in the general population $(P<0.05$ by Mann-Whitney $\mathrm{U}$ test). These findings suggest that patients who visit clinic or hospital complain of two or more symptoms compared with subjects with uninvestigated dyspepsia; in turn, subjects with multiple symptoms may be more likely to seek medications. Finally, it is unknown whether gastroparesis, ${ }^{20}$ a current emerging concept, is included in this type of overlap.

\section{Dyspepsia With Non-gastrointestinal Diseases}

Functional somatic (or pain) syndromes, including fibromyalgia, chronic fatigue syndrome, interstitial cystitis and painful bladder syndrome (or overactive bladder), are known to coexist with FD and irritable bowel syndrome (IBS) in the same individuals. ${ }^{21}$ For example, Chang $^{22}$ showed that up to $50 \%$ of patients with fibromyalgia syndrome complain of symptoms characteristic of dyspepsia. Although the high prevalence of coexisting FD and fibromyalgia suggests common clinical characteristics, 2 studies demonstrated differences in the psychological states between them. In the first, fibromyalgia was associated with panic disorder, while FD was associated with mood disorder. ${ }^{23}$ In

Table 2. Prevalence of Postprandial Distress Syndrome, Epigastric Pain Syndrome and Their Overlap

\begin{tabular}{|c|c|c|c|c|c|c|}
\hline Subjects & Authors & Country & $\mathrm{n}$ & $\operatorname{PDS}(\mathrm{n}[\%])$ & $\operatorname{EPS}(\mathrm{n}[\%])$ & Overlap (n [\%]) \\
\hline \multicolumn{7}{|c|}{ General population } \\
\hline & Zagari et $\mathrm{al}^{13}$ & Italy & 114 & $77(67.5)$ & $55(48.2)$ & $18(15.8)$ \\
\hline & Aro et $\mathrm{al}^{15}$ & Sweden & 157 & $122(77.7)$ & $52(33.1)$ & $17(10.8)$ \\
\hline & Fujiwara et al ${ }^{16}$ & Japan & 269 & $220(81.8)$ & $64(23.8)$ & $15(5.6)$ \\
\hline & Total & & 540 & $419(77.6)$ & $171(31.7)$ & $50(9.3)$ \\
\hline & Wang et $\mathrm{al}^{10}$ & China & 608 & $384(63.2)$ & $385(63.3)$ & $161(26.5)$ \\
\hline & Hsu et $\mathrm{al}^{11}$ & Taiwan & 187 & $94(50.3)$ & $157(84.0)$ & $64(34.2)$ \\
\hline & Manabe et $\mathrm{al}^{12}$ & Japan & 192 & $161(83.9)$ & $111(57.8)$ & $80(41.7)$ \\
\hline & Abid et $\mathrm{al}^{14}$ & Pakistan & 191 & $73(38.2)$ & $165(86.4)$ & $56(29.3)$ \\
\hline & Nwokediuko et $\mathrm{al}^{17}$ & Nigeria & 192 & $120(62.5)$ & $152(79.2)$ & $96(50.0)$ \\
\hline & 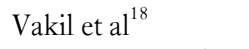 & Europe and Canada & 138 & $99(71.7)$ & $117(84.8)$ & $86(62.3)$ \\
\hline & Total & & 1,586 & $996(62.8)$ & $1,133(71.4)^{\mathrm{a}}$ & $576(36.3)^{\mathrm{a}}$ \\
\hline
\end{tabular}

PDS, postprandial distress syndrome; EPS, epigastric pain syndrome.

${ }^{\mathrm{a}} P<0.05$ versus overlap rate in general population by Mann-Whitney $\mathrm{U}$ test. 
the second, fibromyalgia was associated with mutilation anxiety, while FD was associated with death anxiety. ${ }^{24}$ As well, Van Oudenhove et $\mathrm{al}^{25}$ examined chronic fatigue syndrome-like symptoms in 259 tertiary care FD patients. They found that 102 (39.4\%) patients had chronic fatigue syndrome-like symptoms, and depression and somatization were risk factors for overlapping with chronic fatigue syndrome-like symptoms in FD patients. ${ }^{25}$ Chelimsky et $\mathrm{al}^{26}$ also showed more than $40 \%$ of patients with interstitial cystitis complained of dyspeptic symptoms, including upper abdominal discomfort, bloating, early satiety and nausea. More recently, Matsuzaki et $\mathrm{al}^{27}$ conducted a web surveys regarding overlap of FD (Rome III) and overactive bladder syndrome in 5,494 individuals. They found 438 subjects with FD and 497 with overactive bladder syndrome; of the FD subjects, $20.5 \%$ were diagnosed with overactive bladder syndrome. ${ }^{27}$ Another study by LaMori et $\mathrm{al}^{28}$ showed that 34\% (449/1,297) of patients with atrial fibrillation also reported of dyspepsia. In patients with overlap of dyspepsia/FD and non-GI diseases, we should carefully assess whether such overlap is due to common pathogeneses, ${ }^{29}$ whether dyspeptic symptoms are caused by the underlying disease, or even by medications for the underlying disease.

\section{Dyspepsia With Upper Gastrointestinal Diseases (Heartburn or Gastroesophageal Reflux Disease)}

Jones and Lydeard ${ }^{30}$ examined 2,066 individuals using a postal questionnaire, and found that the prevalence of dyspepsia was $38 \%$ in their sample population, while overlap between dyspepsia and heartburn was found in over half of the subjects with dyspepsia. A similar finding was reported in a larger study conducted in England and Scotland. ${ }^{31}$ Haque et al $^{32}$ also examined the prevalence of dyspepsia and reflux symptoms in 1,000 adults in New Zealand, and found that $63 \%$ of subjects with reflux symptoms had symptoms of dyspepsia, while $56 \%$ of subjects with dyspepsia also had reflux symptoms. Similarly, overlap of GERD with uninvestigated dyspepsia was $13.3 \%$ in Argentina $^{33}$ and $33.8 \%$ in Belgium, ${ }^{34}$ and overlap of GERD was $30-40 \%$ in patients with FD (Rome III) in Japan, ${ }^{35}$ and $48.8 \%$ in subjects with FD (Rome III) in US. ${ }^{36}$ Although there were differences in the prevalence of heartburn or GERD in dyspepsia/FD in each country, overlap of GERD and dyspepsia/FD is clearly a common observation.

GERD is divided into 2 types: non-erosive reflux disease (NERD), defined as the presence of reflux symptoms (e.g., heartburn and acid regurgitation) without esophageal mucosal injury during upper GI endoscopy, and erosive reflux disease (ERD) or erosive esophagitis. Two studies demonstrated that patients with NERD were more frequently overlapped with FD (Rome III), compared to patients with ERD. ${ }^{37,38}$ Interestingly, EPS is the more common subtype of FD to overlap with NERD. ${ }^{38}$

Recent advances in diagnostic tests enable evaluation of all types of reflux, including liquid, gas, acidic, or non-acidic, by using 24-hour multichannel intraluminal impedance $\mathrm{pH}$ (MII-pH) monitoring. ${ }^{39}$ Several studies suggest that NERD is a heterogeneous disease entity. ${ }^{40-42}$ Savarino et $\mathrm{al}^{43}$ examined 200 NERD patients by using MII-pH monitoring, and divided them into the following 3 types: 81 patients with abnormal esophageal acid reflux, 65 patients with positive SAP in the absence of abnormal esophageal acid reflux (hypersensitive esophagus), and 54 patients with negative SAP and normal acid reflux (functional heartburn). They found that patients with functional heartburn had significantly higher prevalence of dyspeptic symptoms, such as postprandial fullness, early satiety, bloating and nausea, but not epigastric pain or burning. ${ }^{43}$ These results suggest that the type of GERD overlapping with dyspepsia/FD has been changed, and narrowed into specific type, from NERD to functional heartburn. Interestingly, dyspepsia that overlapped with NERD was predominantly EPS, ${ }^{38}$ but overlap with functional heartburn primarily showed PDS-like symptoms. ${ }^{43}$

There are several clinical characteristics for overlap of dyspepsia/FD and GERD. Choung et $\mathrm{al}^{36}$ showed that somatization and insomnia were significantly associated with overlap of dyspepsia and GERD, compared to GERD alone or dyspepsia alone. Gwee ${ }^{44}$ showed that predictors of poor response to proton pump inhibitors (PPIs) were bloating, the presence of more than 2 symptoms, anxiety and co-existing IBS. Wang et $\mathrm{al}^{45}$ examined the response of 153 Chinese GERD patients to PPIs, and found that overlap of FD and IBS was significantly associated with PPI failure. These findings emphasize that overlap of GERD with dyspepsia/FD is one of the factors associated with PPI failure in GERD patients. Regarding other types of the functional esophageal disorders, Manabe et $\mathrm{al}^{12}$ demonstrated that $39.8 \%$ of patients with PDS and $44.1 \%$ of patients with EPS (Rome III) showed overlapping with chronic idiopathic nausea syndrome.

\section{Dyspepsia With Lower Gastrointestinal Diseases}

There are many epidemiological studies regarding the overlap of dyspepsia/FD and IBS. Ford et $\mathrm{al}^{46}$ provided a systematic 
review and meta-analysis of the prevalence of IBS in individuals with dyspepsia, by using medical literature published until August 2008. They estimated that the prevalence of dyspepsia in IBS was $27 \%$ (95\% confidence interval $[\mathrm{CI}], 23-31 \%$ ). The prevalence of IBS in subjects with dyspepsia was significantly higher (37\%) than in those without (7\%). They estimated that pooled odds ratio for IBS in subjects with dyspepsia was 8.00 (95\% CI, 5.74-11.16). ${ }^{46}$ Ghoshal et al ${ }^{47}$ summarized the overlap of dyspepsia and IBS in Asia, and showed that the frequency of IBS among patients with FD ranged 1.6-49.0\%. They proposed that the wide range in overlap rates of FD and IBS were due to different diagnostic criteria used for each condition. In addition to these 2 systematic reviews, there are several reports regarding the overlap of dyspepsia/FD and IBS; ${ }^{48-50}$ therefore, it is clear that dyspepsia/FD and IBS frequently overlap. As a result, we will discuss the clinical characteristics of this overlap.

Talley examined 121 IBS patients, including 76 constipation predominant IBS (IBS-C) and 45 diarrhea predominant IBS (IBS-D), with the Hopkins Bowel Symptoms Questionnaire, and found that dyspepsia symptoms (e.g., bloating, early satiety and appetite loss) were more common in patients with IBS-C than in those with IBS-D.$^{51}$ In addition, 2 other studies showed that PDS is the most common type of FD to overlap with IBS. ${ }^{10,52}$ Subjects with overlapping FD (Rome III) and IBS showed a significant increase in the severity of psychopathologic features, including global sensitivity index, obsessive compulsiveness, interpersonal sensitivity, depression, anxiety, anger and hostility, phobic anxiety, paranoid ideation, and psychoticism. ${ }^{53}$ Similarly, Lee et al ${ }^{54}$ showed that depression was significantly associated with the overlap of FD (Rome III) and IBS. One population-based study by Minocha et al ${ }^{55}$ demonstrated that overlap of IBS and dyspepsia (Rome II) was more common in Caucasians than in African Americans, and showed that Caucasians with overlap were likely to be married, live in an urban area, and have low education.

\section{Overlap Between Dyspepsia/Functional Dyspepsia, Gastroesophageal Relux Disease and Irritable Bowel Syndrome}

We have already discussed the overlap of dyspepsia/FD with another, single, GI disease; however, there are also cases of overlap of dyspepsia/FD with multiple GI diseases. The most common form of multiple overlap is dyspepsia/FD, GERD and IBS. Papatheodoridis and Karamanolis ${ }^{56}$ examined prevalence of GI symptoms in 700 Greek urban adults, and identified 339 (48.4\%) subjects with dyspepsia (Gastrointestinal Symptom Rating Scale, and Quality of Life in Reflux and Dyspepsia), 241 (34.4\%) with GERD and 136 (19.4\%) with IBS. In this population, they found multiple overlap of dyspepsia, GERD and IBS in 93 patients (13.3\%). ${ }^{56}$ Lee et $\mathrm{al}^{57}$ examined 1,443 Korean adults, and identified 91 (6.3\%) subjects with dyspepsia (Rome II), 67 (4.6\%) with GERD, 95 (6.6\%) with IBS and multiple overlap of dyspepsia, GERD and IBS in $6(0.4 \%)$ subjects. Hori ${ }^{-58}$ examined 186 Japanese students, and identified 12 (6.7\%) subjects with FD (Rome II), 16 (8.8\%) subjects with GERD, 40 (22.1\%) subjects with IBS and $2(1.1 \%)$ subjects with overlap of all three diseases. Kaji et al ${ }^{59}$ examined 2,680 Japanese adults, and identified 269 (10.0\%) subjects with FD (Rome III), 207 (8.8\%) subjects with GERD, 381 (14.2\%) subjects with IBS and 29 (1.1\%) subjects with overlap of all 3 diseases. Fujiwara et $\mathrm{al}^{60}$ also showed decreased health-related quality of life (HR-QOL; both physical and mental) in subjects with overlap of all 3 diseases, compared to the non-overlap group, and identified that cigarette smoking was a common risk factor for overlap of all 3 diseases. Similarly, De Vries et $\mathrm{al}^{61}$ showed that patients with overlap of FD (Rome II), IBS, or both, had significantly poorer HR-QOL among 263 GERD patients. Futagami et al ${ }^{62}$ studied 139 patients with FD (Rome III), 14 patients with IBS and 12 patients with NERD, and identified 23 with overlap of all 3 diseases. They also found that patients with overlap had more severe symptoms, and might be associated with sleep disturbances, compared to patients without overlap. In contrast, Aro et a ${ }^{15}$ conducted a population-based study in 1,001 Swedish adults, and identified 157 (15.7\%) subjects with FD (Rome III), 400 (40.0\%) subjects with GERD, 296 (29.6\%) subjects with IBS and 58 (5.8\%) subjects with overlap of all three diseases. They found a significant decrease in bodily pain scores only among HR-QOL items in patients with overlap. We have summarized the prevalence of overlaps with GERD and IBS, GERD only and IBS only among subjects with dyspepsia/FD in Table 3. Among patients with dyspepsia/FD, 19.8-52.4\% had pure dyspepsia/FD while 6.6-36.9\% showed overlap of dyspepsia/FD, GERD and IBS.

To summarize our epidemiological findings, internal subgroup overlap in FD is common, especially in patients. Dyspepsia/FD overlapping with GI diseases, including reflux diseases and IBS, is also common. Subjects with this overlap have more frequent and severe symptoms, poorer HR-QOL and higher somatization scores, and are likely to have anxiety, depression or insomnia. These patients frequently do not respond to standard therapy, especially PPIs in cases of overlap between GERD and 
Table 3. Prevalence of Overlap in Gastroesophageal Reflux Disease and/or Irritable Bowel Syndrome in Subjects With Dyspepsia/ Functional Dyspepsia

\begin{tabular}{|c|c|c|c|c|c|c|c|c|}
\hline \multirow{2}{*}{ Authors } & \multirow{2}{*}{ Country } & \multirow{2}{*}{ Subjects } & \multirow{2}{*}{$\mathrm{n}$} & \multirow{2}{*}{$\begin{array}{l}\text { Dyspepsia/FD } \\
\text { (n [\%]) }\end{array}$} & \multicolumn{4}{|c|}{ Subjects with dyspepsia/FD (\%) } \\
\hline & & & & & No-overlap & + GERD only & + IBS only & + GERD + IBS \\
\hline $\begin{array}{l}\text { Papatheodoridis and } \\
\text { Karamanolis }^{56}\end{array}$ & Greek & Population & 700 & $339(48)$ & 29.5 & $26.3^{\mathrm{a}}$ & 11.5 & $32.7^{\mathrm{a}}$ \\
\hline Lee et $\mathrm{al}^{57}$ & Korea & Population & 1,443 & $91(6)$ & 49.5 & $30.0^{\mathrm{b}}$ & 14.3 & $6.6^{\mathrm{b}}$ \\
\hline Hori et $\mathrm{al}^{58}$ & Japan & Students & 186 & $12(7)$ & 25.4 & $9.0^{\mathrm{a}}$ & 49.3 & $16.4^{\mathrm{a}}$ \\
\hline Kaji et al ${ }^{59}$ & Japan & Population & 2,680 & $269(10)$ & 52.4 & $13.4^{\mathrm{b}}$ & 23.4 & $10.8^{\mathrm{b}}$ \\
\hline Aro $\mathrm{al}^{15}$ & Sweden & Population & 1,001 & $157(16)$ & 19.8 & $24.8^{\mathrm{c}}$ & 18.5 & $36.9^{c}$ \\
\hline 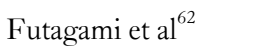 & Japan & Patients & 139 & $139(100)$ & 42.7 & $21.6^{\mathrm{c}}$ & 19.4 & $16.5^{\mathrm{c}}$ \\
\hline
\end{tabular}

${ }^{a}$ Diagnosis of gastroesophageal reflux disease (GERD) was performed by presence of heartburn and/or acid regurgitation using Gastrointestinal Symptom Rating Scale, bresence of heartburn and/or acid regurgitation at least once a week or c presence of heartburn and/or acid regurgitation.

FD, functional dyspepsia; GERD, gastroesophageal reflux disease; IBS, irritable bowel syndrome.

dyspepsia/FD. Finally, we believe that the high prevalence of overlap in patients with dyspepsia/FD is not coincidence, and we suggest the presence of common pathogeneses.

\section{Pathogenesis}

Several pathogenic mechanisms for FD have been proposed. They include altered GI motility, visceral hypersensitivity, nervous system dysregulation, peripheral immune activation, infectious etiology, low-grade inflammation, genetic susceptibility, psychological distress and stressful early life events. ${ }^{63,64}$ However, there are a few reports regarding the specific pathogenesis of overlap in patients with FD.

\section{Genetic Susceptibility}

Several studies showed genetic associations with FD, including genetic polymorphisms in the G-protein beta-3 subunit C825T (GNB3-C825T), serotonin transporter, IL-17F and transient receptor potential vanilloid type $1 .{ }^{65}$ Andresen ${ }^{66}$ showed that GNB3-C825T was associated with FD, but not with overlap of FD (Rome II) and IBS. Two Korean studies showed that serotonin transporter and GNB3-C825T genetic polymorphisms were not associated with FD (Rome III), nor were they associated with FD and IBS overlap. ${ }^{67,68}$ Therefore, there is currently no evidence of genetic factors playing a part in the overlap of FD and IBS.

\section{Gastrointestinal Motility}

Stanghellini et al ${ }^{69}$ examined gastric emptying in 146 IBS patients by using scintigraphy, as well as dyspeptic symptoms by using a validated questionnaire. Dyspepsia was found in 96 (66\%) patients, with patients complaining of postprandial fullness $(88 \%)$, epigastric pain (48\%), nausea (30\%) and vomiting (9\%). They found a higher prevalence of abnormal gastric emptying in patients with IBS and dyspepsia compared with those only with IBS, in both men and women. Gastric emptying in IBS overlapping dyspepsia was significantly delayed compared to IBS without dyspepsia or healthy controls. They also found a significant positive association between delayed gastric emptying and postprandial fullness and nausea in IBS patients. However, as they did not include patients with dyspepsia only, nor did they examine colonic motility, it is unknown whether altered motility of the entire GI tract is present in overlap of FD and IBS.

\section{Visceral Hypersensitivity}

Holtmann et $\mathrm{al}^{70}$ used barostat devices to evaluate small intestinal mechano-sensitive function in 22 randomly selected patients (with FD, IBS or both) from a total of 157 affected patients and 22 healthy controls. They found that the threshold of first perception and the maximum tolerated pressure was significantly lower in patients compared to controls. However, there were no differences in these parameters among the FD, IBS and overlap groups. ${ }^{70}$ Corsetti et $\mathrm{al}^{71}$ examined $309 \mathrm{FD}$ (Rome II) patients, including $46 \%$ with overlap of FD and IBS, by using gastric barostats to determine sensitivity to distension, accommodation of food and gastric emptying breath tests. They found the threshold for first perception and maximum tolerated pressure was significantly lower in FD overlapping IBS, compared with FD alone. They also showed that there were no differences between patients with FD alone and FD/IBS overlap, when they measured delayed gastric emptying for both liquid and solid meals, or impaired accommodation. ${ }^{71}$ The results of Corsetti et al ${ }^{71}$ suggest 
that visceral hypersensitivity plays a significant role in the overlap of FD and IBS. Recently, Lee et $\mathrm{al}^{72}$ described the role of mucosal mast cells in overlap among patients with non-cardiac chest pain (NCCP). They found a positive correlation between esophageal and duodenal mucosal mast cell counts, though this only existed in patients with overlap of NCCP and FD (Rome III). In addition, they found that patients with IBS showed a strong positive correlation between esophageal and rectal mucosal mast cell numbers. ${ }^{72}$ As mucosal mast cells are associated with visceral hypersensitivity, infiltration of mast cells into the GI mucosa may play a role in the pathogenesis of overlap by inducing hypersensitivity to dietary stimulants.

\section{Infectious Etiology}

One Spanish study revealed the prevalence of uninvestigated dyspepsia (Rome II) and IBS through a cohort study, evaluating patients 3, 6 and 12 months after a Salmonella gastroenteritis outbreak. ${ }^{73}$ They found that prevalence of dyspepsia, IBS or overlap at baseline was similar in subjects who experienced acute gastroenteritis $(n=677)$ and those without $(n=1,201)$. However, the prevalence of dyspepsia and IBS had significantly increased in subjects who experienced acute gastroenteritis at 3,6 and 12 months. Among them, a significant number of patients met the clinical criteria for both dyspepsia and IBS (23-36\% at each follow-up point). In patients with dyspepsia, the overlap with IBS was $35 \%, 33 \%$ and $46 \%$ at 3, 6 and 12 months, respectively. Inpatients with IBS, the overlap with dyspepsia was $70 \%, 54 \%$ and $62 \%$ at 3, 6 and 12 months, respectively. As several studies demonstrated the presence of post-infectious IBS $^{74}$ and post-infectious $\mathrm{FD},{ }^{75}$ these results confirmed the presence of post-infectious overlap of dyspepsia/FD and IBS.

\section{Stressful Early Life Events}

Stressful early life events are one of the pathogenic factors in functional GI disorders, ${ }^{76}$ although there is no clinical data regarding overlap in patients with dyspepsia/FD. Tominaga et $\mathrm{al}^{77}$ and Fujikawa et $\mathrm{al}^{78}$ examined experimental models in rats by using maternal separation at childhood and waster immersion stress later in life, and found similar morphological changes for each, including elongation and sprouting in enteric glia cells in both the stomach and colon. Such morphological changes revealed reactive gliosis, and induced glio-neural transmission disorder. Functional GI motility assessment also revealed delayed gastric emptying and colonic hyper-contraction in rats with maternal separation and water immersion stress compared to controls. ${ }^{77,78}$
Therefore, stressful early life events might cause functional abnormality in the entire GI tract through morphological changes to enteric glia cells, and thus might induce the overlap of FD and IBS.

In summary, there is not enough data to conclusively explain the common pathogeneses of overlap in patients with dyspepsia/FD, though visceral hypersensitivity, or altered GI motility might be associated.

\section{Treatment for Overlaps in Patients With Dyspepsia/Functional Dyspepsia}

Treatment of FD is difficult, and does not currently produce satisfactory results. ${ }^{63,79}$ Camilleri and Tack $^{80}$ proposed that first line treatment be divided according to FD subtypes: PPIs for EPS, and prokinetics (including acotiamide) and/or 5-hydroxytryptamine $1 \mathrm{~A}$ agonist for PDS. If these treatments are not effective, PPIs could then be used for PDS, and prokinetics for EPS, as the second line treatment. Finally, in cases of no responses to these drugs, antidepressants could be used. ${ }^{80}$ However, there does not appear to be a consensus regarding the efficacy of these treatments.

Only a few randomized clinical trials have evaluated drugs targeting FD overlapping with other GI disorders. Monnkes examined the efficacy of pantoprazole in 626 patients with reflux esophagitis, examining the prevalence of FD (Rome II/III modified) or IBS symptoms at baseline, during treatment and during an observation period up to 6 months. They found PPIs significantly improved the reflux symptoms, as well as FD or IBS symptoms. Cessation of PPI treatment induced a recurrence of the reflux symptoms, but relief of FD or IBS symptoms was maintained after cessation of PPIs. ${ }^{81}$ Although a detailed mechanism of these effects of PPIs is unknown, they might be due to a placebo effect for symptoms of FD and IBS, or recurrence of FD or IBS symptoms may take longer than those of reflux. One small, randomized controlled trial with tegaserod (a 5-hydroxytryptamine 4 agonist) was reported, where 25 patients with overlapping functional heartburn and FD (Rome II) were randomized to receive tegaserod or a placebo. Although tegaserod did not affect the primary outcome (barostat balloon volume for pain and overall symptom improvement), tegaserod improved gastric pain and reduced the severity of heartburn, regurgitation, early satiety and bloating. ${ }^{82}$ These results suggest the possibility of efficacy of prokinetics for overlap, but larger studies are necessary to confirm this possibility. 
Table 4. Summary of Overlap in Patients With Dyspepsia/Functional Dyspepsia

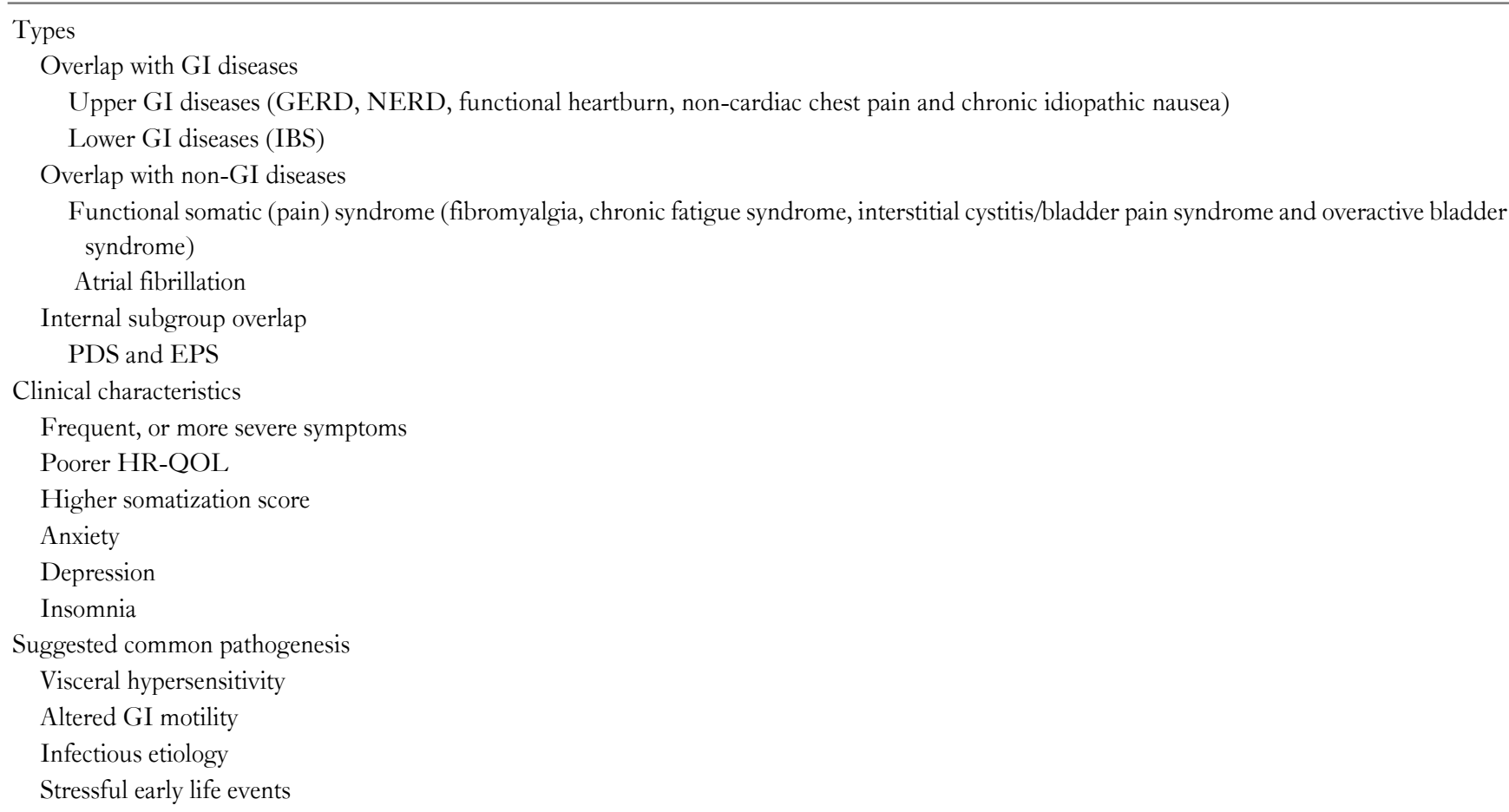

GI, gastrointestinal; GERD, gastroesophageal reflux disease; NERD, non-erosive reflux disease; IBS, irritable bowel syndrome; PDS, postprandial distress syndrome; EPS, epigastric pain syndrome; HR-QOL, health related-quality of life.

There are many unsolved questions regarding the treatment of overlap in patients with dyspepsia/FD. Should we choose same strategy for FD treatment, proposed by Camilleri and Tack $?^{80}$ If a case of FD overlaps with GERD, should PPIs be the first line treatment? If a case of FD overlaps with IBS-C, should prokinetics be the first choice? Should we choose anti-depressants or psychotherapy as the first line of treatment in cases of overlap with anxiety, depression or insomnia? Unfortunately, answers to these questions are not readily available, and must be addressed with well-designed clinical trials.

\section{Conclusion}

Our summary of overlap in patients with dyspepsia/FD is shown in Table 4. Overlap of dyspepsia/FD in patients with GI or non-GI diseases is common. These patients showed more frequent and severe symptoms, poorer HR-QOL and lower response to treatment. It is possible that common pathogenic mechanisms may be responsible for overlap, but further studies are necessary. In addition, a comprehensive therapeutic strategy for overlap has not yet been established.
Our review focused primarily on IBS or GERD in patients with dyspepsia/FD, although both upper and lower GI symptoms overlap is very common, and a majority of suffers reported an additional complex symptoms. ${ }^{83}$ In the future, overlap of dyspepsia/FD with other functional GI diseases, especially those without reflux, should be examined. Finally, given that Agréus et $\mathrm{al}^{84}$ showed that approximately half of overlap patients changed their symptom profile over a 1-year period, future discussions should examine whether we should separate disease entities in patients with overlap.

\section{Acknowledgements}

This paper was presented at the 5th Asian Postgraduate Course on Neurogastroenterology and Motility (APNM 2014), Seoul, Korea.

\section{References}

1. El-Serag HB, Talley NJ. Systemic review: the prevalence and clinical course of functional dyspepsia. Aliment Pharmacol Ther 2004; 
19:643-654.

2. Drossman DA. Rome III: The functional gastrointestinal disorders, 3rd ed. MacLean, VA: Degnon Associates, Inc., 2006.

3. Tack J, Talley NJ, Camilleri M, et al. Functional gastroduodenal disorders. Gastroenterology 2006;130:1466-1479.

4. Colin-Jones DG. Management of dyspepsia: report of a working party. Lancet 1988;331:576-579.

5. Drossman DA, Corrazziari E, Talley NJ, et al. Rome II: The functional gastrointestinal disorders. 2nd ed. McLean: Degnon, 2000.

6. Talley NJ, Zinsmeister AR, Schleck CD, Melton LJ 3rd. Dyspepsia and dyspepsia subgroups: a population-based study. Gastroenterology 1992;102(4 Pt 1):1259-1268.

7. Schlemper RJ, van der Werf SD, Vandenbroucke JP, Biemond I, Lamers CB. Peptic ulcer, non-ulcer dyspepsia and irritable bowel syndrome in The Netherlands and Japan. Scand J Gastroenterol 1993; 28(suppl 200):33-41.

8. Inoue M, Sekiguchi T, Harasawa S, Miwa T, Miyoshi A. Dyspepsia and dyspepsia subgroups in Japan: symptom profiles and experience with cisapride. Scand J Gastroenterol 1993;28(suppl 195):36-38; discussion 38-39.

9. Penston JG, Pounder RE. A survey of dyspepsia in Great Britain. Aliment Pharmacol Ther 1996;10:83-89.

10. Wang A, Liao X, Xiong L, et al. The clinical overlap between functional dyspepsia and irritable bowel syndrome based on Rome III criteria. BMC Gastroenterol 2008;8:43.

11. Hsu YC, Liou JM, Liao SC, et al. Psychopathology and personality trait in subgroups of functional dyspepsia based on Rome III criteria. Am J Gastroenterol 2009; 104:2534-2542.

12. Manabe N, Haruma K, Hata J, et al. Clinical characteristics of Japanese dyspeptic patients: is the Rome III classification applicable? Scand J Gastroenterol 2010;45:567-572.

13. Zagari RM, Law GR, Fuccio L, et al. Epidemiology of functional dyspepsia and subgroups in the Italian general population: an endoscopic study. Gastroenterology 2010;138:1302-1311.

14. Abid S, Siddiqui S, Jafri W. Discriminant value of Rome III questionnaire in dyspeptic patients. Saudi J Gastroenterol 2011;17:129-133.

15. Aro P, Talley NJ, Agréus L, et al. Functional dyspepsia impairs quality of life in the adult population. Aliment Pharmacol Ther 2011;33:1215-1224.

16. Fujiwara Y, Kubo M, Kohata Y, et al. Risk factors associated with dyspepsia in Japanese adults.J Clin Gastroenterol 2011;45:567-568.

17. Nwokediuko SC, Ijoma U, Obienu O. Functional dyspepsia: subtypes, risk factors, and overlap with irritable bowel syndrome in a population of African patients. Gastroenterol Res Pract 2012;2012: 562393.

18. Vakil N, Halling K, Ohlsson L, Wernersson B. Symptom overlap between postprandial distress and epigastric pain syndromes of the Rome III dyspepsia classification. Am J Gastroenterol 2013;108:767-774.

19. Yamawaki H, Futagami S, Shimpuku M, et al. Impact of sleep disorders, quality of life and gastric emptying in distinct subtypes of functional dyspepsia in Japan. J Neurogastroenterol Motil 2014;20: 104-112.

20. Ates F, Vaezi MF. New approaches to management of PPI-refractory gastroesophageal reflux disease. Curr Treat Options Gastroenterol 2014;12:18-33.

21. Henningsen P, Zipfel S, Herzog W. Management of functional so- matic syndromes. Lancet 2007;369:946-955.

22. Chang $\mathrm{L}$. The association of functional gastrointestinal disorders and fibromyalgia. Eur J Surg Suppl 1998;583:32-36.

23. Malt EA, Berle JE, Olafsson S, Lund A, Ursin H. Fibromyalgia is associated with panic disorder and functional dyspepsia with mood disorders. A study of women with random sample population controls. J Psychosom Res 2000;49:285-289.

24. Malt EA, Ursin H. Mutilation anxiety differs among females with fibromyalgia and functional dyspepsia and population controls. J Psychosom Res 2003;54:523-531.

25. Van Oudenhove L, Vandenberghe J, Vos R, Holvoet L, Tack J. Factors associated with co-morbid irritable bowel syndrome and chronic fatigue-like symptoms in functional dyspepsia. Neurogastroenterol Motil 2011;23:524, e202.

26. Chelimsky G, Heller E, Buffington CA, Rackley R, Zhang D, Chelimsky T. Co-morbidities of interstitial cystitis. Front Neurosci 2012;6:114

27. Matsuzaki J, Suzuki H, Fukushima Y, et al. High frequency of overlap between functional dyspepsia and overactive bladder. Neurogastroenterol Motil 2012;24:821-827.

28. LaMori JC, Mody SH, Gross HJ, et al. Dyspepsia and disease burden among patients with atrial fibrillation. Crit Pathw Cardiol 2012; 11:14-19.

29. Kim SE, Chang L. Overlap between functional GI disorders and other functional syndromes: what are the underlying mechanisms? Neurogastroenterol Motil 2012;24:895-913.

30. Jones R, Lydeard S. Prevalence of symptoms of dyspepsia in the community. BMJ 1989;298:30-32.

31. Jones RH, Lydeard SE, Hobbs FD, et al. Dyspepsia in England and Scotland. Gut 1990;31:401-405.

32. Haque M, Wyeth JW, Stace NH, Talley NJ, Green R. Prevalence, severity and associated features of gastro-oesophageal reflux and dyspepsia: a population-based study. N Z Med J 2000;113:178-181.

33. Olmos JA, Pogorelsky V, Tobal F, et al. Uninvestigated dyspepsia in Latin America: a population-based study. Dig Dis Sci 2006;51: 1922-1929.

34. Piessevaux H, De Winter B, Louis E, et al. Dyspeptic symptoms in the general population: a factor and cluster analysis of symptom groupings. Neurogastroenterol Motil 2009;21:378-388

35. Ohara S, Kawano T, Kusano M, Kouzu T. Survey on the prevalence of GERD and FD based on the Montreal definition and the Rome III criteria among patients presenting with epigastric symptoms in Japan. J Gastroenterol 2011;46:603-611.

36. Choung RS, Locke GR 3rd, Schleck CD, Zinsmeister AR, Talley NJ. Overlap of dyspepsia and gastroesophageal reflux in the general population: one disease or distinct entities? Neurogastroenterol Motil 2012;24:229-234, e106.

37. Savarino V, Savarino E. Is acid relevant in the genesis of dyspeptic symptoms associated with nonerosive reflux disease? Eur J Gastroenterol Hepatol 2008;20:252-254.

38. Noh YW, Jung HK, Kim SE, Jung SA. Overlap of erosive and non-erosive reflux diseases with functional gastrointestinal disorders according to Rome III criteria. J Neurogastroenterol Motil 2010;16: 148-156.

39. Zerbib F, Roman S, Ropert A, et al. Esophageal $\mathrm{pH}$-impedance monitoring and symptom analysis in GERD: a study in patients off 
and on therapy.Am J Gastroenterol 2006;101:1956-1963.

40. Sifrim D, Zerbib F. Diagnosis and management of patients with reflux symptoms refractory to proton pump inhibitors. Gut 2012;61: 1340-1354.

41. Kohata Y, Fujiwara Y, Machida H, et al. Pathogenesis of proton-pump inhibitor-refractory non-erosive reflux disease according to multichannel intraluminal impedance-pH monitoring. J Gastroenterol Hepatol 2012;27(suppl 3):58-62.

42. Iwakiri K, Kawami N, Sano H, et al. Acid and non-acid reflux in Japanese patients with non-erosive reflux disease with persistent reflux symptoms, despite taking a double-dose of proton pump inhibitor: a study using combined $\mathrm{pH}$-impedance monitoring. J Gastroenterol 2009;44:708-712.

43. Savarino E, Pohl D, Zentilin P, et al. Functional heartburn has more in common with functional dyspepsia than with non-erosive reflux disease. Gut 2009;58:1185-1191.

44. Gwee KA, Hwang JE, Ho KY, Yeoh KG, Lum CF, Ang PK. In-practice predictors of response to proton pump inhibitor therapy in primary care patients with dyspepsia in an Asian population. J Clin Gastroenterol 2008;42:134-138.

45. Wang AJ, Wang $\mathrm{H}, \mathrm{Xu} \mathrm{L}$, et al. Predictors of clinical response of acid suppression in Chinese patients with gastroesophageal reflux disease. Dig Liver Dis 2013;45:296-300.

46. Ford AC, Marwaha A, Lim A, Moayyedi P. Systematic review and meta-analysis of the prevalence of irritable bowel syndrome in individuals with dyspepsia. Clin Gastroenterol Hepatol 2010;8:401-409.

47. Ghoshal UC, Singh R, Chang FY, et al. Epidemiology of uninvestigated and functional dyspepsia in Asia: facts and fiction. $\mathrm{J}$ Neurogastroenterol Motil 2011;17:235-244.

48. Suzuki H, Hibi T. Overlap syndrome of functional dyspepsia and irritable bowel syndrome - are both diseases mutually exclusive? J Neurogastroenterol Motil 2011;17:360-365.

49. Nakajima S, Takahashi K, Sato J, et al. Spectra of functional gastrointestinal disorders diagnosed by Rome III integrative questionnaire in a Japanese outpatient office and the impact of overlapping. J Gastroenterol Hepatol 2010;25(suppl 1):S138-S143

50. Perveen I, Rahman MM, Saha M, Rahman MM, Hasan MQ. Prevalence of irritable bowel syndrome and functional dyspepsia, overlapping symptoms, and associated factors in a general population of Bangladesh. Indian J Gastroenterol 2014;33:265-273.

51. Talley NJ, Dennis EH, Schettler-Duncan VA, Lacy BE, Olden KW, Crowell MD. Overlapping upper and lower gastrointestinal symptoms in irritable bowel syndrome patients with constipation or diarrhea. Am J Gastroenterol 2003;98:2454-2459.

52. Matsuzaki J, Suzuki H, Asakura K, et al. Classification of functional dyspepsia based on concomitant bowel symptoms. Neurogastroenterol Motil 2012;24:325, e164.

53. Piacenti no D, Cantarini R, Alfonsi M, et al. Psychopathological features of irritable bowel syndrome patients with and without functional dyspepsia: a cross sectional study. BMC Gastroenterol 2011;11:94.

54. Lee HJ, Lee SY, Kim JH, et al. Depressive mood and quality of life in functional gastrointestinal disorders: differences between functional dyspepsia, irritable bowel syndrome and overlap syndrome. Gen Hosp Psychiatry 2010;32:499-502.

55. Minocha A, Chad W, Do W, Johnson WD. Racial differences in epidemiology of irritable bowel syndrome alone, un-investigated dys- pepsia alone, and "overlap syndrome" among africanamericans compared to Caucasians: a population-based study. Dig Dis Sci 2006;51: 218-226.

56. Papatheodoridis GV, Karamanolis DG. Prevalence and impact of upper and lower gastrointestinal symptoms in the Greek urban general population. Scand J Gastroenterol 2005;40:412-421.

57. Lee SY, Lee KJ, Kim SJ, Cho SW. Prevalence and risk factors for overlaps between gastroesophageal reflux disease, dyspepsia, and irritable bowel syndrome: a population-based study. Digestion 2009; 79:196-201

58. Hori K, Matsumoto T, Miwa H. Analysis of the gastrointestinal symptoms of uninvestigated dyspepsia and irritable bowel syndrome. Gut Liver 2009;3:192-196.

59. Kaji M, Fujiwara Y, Shiba M, et al. Prevalence of overlaps between GERD, FD and IBS and impact on health-related quality of life. J Gastroenterol Hepatol 2010;25:1151-1156.

60. Fujiwara Y, Kubo M, Kohata Y, et al. Cigarette smoking and its association with overlapping gastroesophageal reflux disease, functional dyspepsia, or irritable bowel syndrome. Intern Med 2011;50:24432447.

61. De Vries DR, Van Herwaarden MA, Baron A, Smout AJ, Samsom M. Concomitant functional dyspepsia and irritable bowel syndrome decrease health-related quality of life in gastroesophageal reflux disease. Scand J Gastroenterol 2007;42:951-956.

62. Futagami S, Yamawaki H, Shimpuku M, et al. Impact of coexisting irritable bowel syndrome and non-erosive reflux disease on postprandial abdominal fullness and sleep disorders in functional dyspepsia. J Nippon Med Sch 2013;80:362-370.

63. Miwa H. Whydyspepsia can occur without organic disease: pathogenesis and management of functional dyspepsia. J Gastroenterol 2012; $47: 862-871$

64. Tack J, Masaoka T, Janssen P. Functional dyspepsia. Curr Opin Gastroenterol 2011;27:549-557.

65. Oshima T, Toyoshima F, Nakajima S, Fukui H, Watari J, Miwa H. Genetic factors for functional dyspepsia. J Gastroenterol Hepatol 2011;26(suppl 3):83-87.

66. Andresen V, Camilleri M, Kim HJ, et al. Is there an association between GNbeta3-C825T genotype and lower functional gastrointestinal disorders? Gastroenterology 2006;130:1985-1994.

67. Kim HG, Lee KJ, Lim SG, Jung JY, Cho SW. G-protein Beta3 subunit $\mathrm{C} 825 \mathrm{~T}$ polymorphism in patients with overlap syndrome of functional dyspepsia and irritable bowel syndrome. J Neurogastroenterol Motil 2012;18:205-210.

68. Park H. Functional gastrointestinal disorders and overlap syndrome in Korea. J Gastroenterol Hepatol 2011;26(suppl 3):12-14.

69. Stanghellini V, Tosetti C, Barbara G, et al. Dyspeptic symptoms and gastric emptying in the irritable bowel syndrome. Am J Gastroenterol 2002;97:2738-2743

70. Holtmann G, Goebell H, Talley NJ. Functional dyspepsia and irritable bowel syndrome: is there a common pathophysiological basis? Am J Gastroenterol 1997;92:954-959.

71. Corsetti M, Caenepeel P, Fischler B, Janssens J, Tack J. Impact of coexisting irritable bowel syndrome on symptoms and pathophysiological mechanisms in functional dyspepsia. Am J Gastroenterol 2004;99:1152-1159

72. Lee H, Chung H, Park JC, Shin SK, Lee SK, Lee YC. Heterogene- 
ity of mucosal mast cell infiltration in subgroups of patients with esophageal chest pain. Neurogastroenterol Motil 2014;26:786-793.

73. Mearin F, Pérez-Oliveras M, Perelló A, et al. Dyspepsia and irritable bowel syndrome after a Salmonella gastroenteritis outbreak: one-year follow-up cohort study. Gastroenterology 2005;129:98-104.

74. Ghoshal UC, Ranjan P. Post-infectious irritable bowel syndrome: the past, the present and the future. J Gastroenterol Hepatol 2011; 26(suppl 3):94-101.

75. Futagami S, Shindo T, Kawagoe T, et al. Migration of eosinophils and CCR2-/CD68-double positive cells into the duodenal mucosa of patients with postinfectious functional dyspepsia. Am J Gastroenterol 2010;105:1835-1842.

76. Drossman DA. The functional gastrointestinal disorders and the Rome III process. Gastroenterology 2006;130:1377-1390.

77. Tominaga K, Fujikawa Y, Tanaka F, et al. Structural plasticity of gastric glial cells as responses to early life stress (maternal separation) and acute stress in adulthood in rats. Gastroenterology 2013;144:S57.

78. Fujikawa Y, Tominaga K, Tanaka F, et al. Structural plasticity of colonic glial cells enhanced by acute stress in adulthood was associated with colonic hyper-contraction in maternally separated rats. Gastroenterology 2013;144:S371.
79. Saad RJ, Chey WD. Review article: current and emerging therapies for functional dyspepsia. Aliment Pharmacol Ther 2006;24:475-492.

80. Camilleri M, Tack JF. Current medical treatments of dyspepsia and irritable bowel syndrome. Gastroenterol Clin North Am 2010;39: 481-493.

81. Mönnikes H, Schwan T, van Rensburg C, et al. Randomised clinical trial: sustained response to PPI treatment of symptoms resembling functional dyspepsia and irritable bowel syndrome in patients suffering from an overlap with erosive gastro-oesophageal reflux disease. Aliment Pharmacol Ther 2012;35:1279-1289.

82. Miner PB Jr, Rodriguez-Stanley S, Proskin HM, Kianifard F, Bottoli I. Tegaserod in patients with mechanical sensitivity and overlapping symptoms of functional heartburn and functional dyspepsia. Curr Med Res Opin 2008;24:2159-2172.

83. Locke GR 3rd, Zinsmeister AR, Fett SL, Melton LJ 3rd, Talley NJ. Overlap of gastrointestinal symptom complexes in a US community. Neurogastroenterol Motil 2005;17:29-34.

84. Agréus L, Svärdsudd K, Nyrén O, Tibblin G. Irritable bowel syndrome and dyspepsia in the general population: overlap and lack of stability over time. Gastroenterology 1995;109:671-680. 